ESJ Social Sciences

\title{
WhatsApp: Communication between Parents and Kindergarten Teachers in the Digital Era
}

\author{
Aviva Dan \\ Eitan Simon \\ Ohalo Academic College, Israel
}

Doi:10.19044/esj.2021.v17n12p1

Submitted: 05 February 2021

Accepted: 26 March 2021

Published: 30 April 2021
Copyright 2021 Author(s)

Under Creative Commons BY-NC-ND

4.0 OPEN ACCESS

Cite As:

Aviva, D. and Simon, E. (2021). WhatsApp: Communication between Parents and Kindergarten Teachers in the Digital Era. European Scientific Journal, ESJ, 17(12), 1. https://doi.org/10.19044/esj.2021.v17n12p1

\begin{abstract}
The technological revolution has filtered into the field of education and among other things, affects communication between parents and teachers in schools and in kindergartens. A digital method for interpersonal communications enables the immediate transfer of messages to a large number of recipients, which is efficient and ensures transparency of actions and policies. The WhatsApp application is now widely used in correspondence between parents and schools, including in kindergartens. The research investigated how kindergarten teachers in Israel use the social media "WhatsApp" in communication with their parents. Using a quantitative research approach, a specially designed questionnaire was distributed online as a Google.docs document to 161 kindergarten teachers in the North of Israel. The kindergarten teachers reported that they were open to change and willing to adopt new technologies that can help them in their work. However, it appears that the main adoption and use of the WhatsApp tool is for the transmission of information or kindergarten experiences to the parents. The kindergarten teachers felt that the WhatsApp application was advantageous due to its easy accessibility and speed of communication and testified to more sharing and involvement of the parents in the kindergarten activities and work. Nevertheless, several questions led to concerns about the
\end{abstract}


mutual availability of the information that is transmitted, the type of information, and the extent of need for the use of this tool in the present era.

Keywords: Kindergarten teachers, digital era, digital communication, kindergarten teachers-parents' communication

\section{Introduction}

Modern societies are undergoing a dynamic ongoing revolution due to the dramatic development of technology all over the world, opening innumerable sources of information to everyone, and facilitating interpersonal communication through digital means and the social networks. This technological revolution has filtered into the field of education and among other things, affects communication between parents and teachers in schools and in kindergartens. Today, communication between these educators (parents and teachers) is conducted through various means including traditional methods, teacher-parents conferences, telephone calls, letters, and through digital mail and online social networks. The use of digital methods for interpersonal communication enables the immediate transfer of messages to a large number of recipients, and it is efficient and ensures transparency of actions and policies (Sword, 2014). There are also disadvantages to this form of communication, whereby negative messages are immediately transferred between a large number of people and also affect personal opinions. In the field of education, this may include parents expressing negative opinions about teachers and consequently influencing other parents' opinions.

The ability of teacher-parents communication to advance children's wellbeing has been investigated by a number of research studies (Kuusimaki et al., 2019; Baker et al., 2016). Bronfenbrenner (1979) suggested that a child develops within different circles of influence (their immediate family, schools or kindergartens' communities) and the child's environmental culture and the child's development is affected by the quality of the mutual relationships between these different circles of influence. In Israel, familyschool relations are perceived as being strained and complex $(\mathrm{Tal} \& \mathrm{Bar}$, 2010). The literature in this field relates to two models describing the style of communication between parents and teachers in Israel, which includes; the separation model and the collaboration model (Tal \& Bar, 2010).

The history of parent-teacher relationships in Israel shows that between the years 1930-1950, the two systems, families and schools, were completely different. More recently, the model of collaboration has been adopted more frequently. Until today, there is no conceptual model used by all schools for teacher-parent communication or collaboration (Tal \& Bar, 2010). 


\section{Models of Parent- Teacher Communication The Separation Model}

The separation model describes the total separation of areas of responsibility and action between the parents and the educational system. In the schools, the teachers have total responsibility and authority, whereas in the children's homes, the parents are considered to have total responsibility and authority (Tal \& Bar, 2010). The relationship between parents and teachers is conducted through the child, and it mainly involves passing important information (New et al., 2000).

\section{The Collaboration Model}

In this model of communication, the limits and areas of responsibility of each system are not clearly defined, nor are the expectations of each party from each other. There is a lack of consensus in the research literature regarding the definition of this model. Therefore, the Israeli Ministry of Education has identified 14 different definitions for this model relating to the manner of collaboration and communication between parents and teachers (Israel Ministry of Education, 2003). The areas of parents' involvement in the school and the willingness of the educational staff to make room for the parents' involvement in schools are often in dispute (Gur \& Zalmanson-Levi, 2005; Epstein \& Sheldon, 2002).

\section{Kindergarten Teacher-Parents Communication}

Through their Internet site and protocols, the Israeli Ministry of Education tries to advance the values of cooperation between parents and kindergarten teachers. Therefore, this indicates that a strong level of cooperation between these two authorities is important for the child's success.

According to Epstein (2001), parents often wish to be involved in the activities that take place in their children's kindergarten but lack the knowledge and skills needed to convey this expectation to the kindergarten teachers. Some parents expect the kindergarten teachers to take the initiative in nurturing the relationship and maintaining communication, while others are caught up in their daily schedules and work obligations that they are not available to develop the relationship (Christenson, 2004).

The levels of interaction in kindergartens between parents and staff differ to those in schools. The parents accompany their children in the morning to the kindergarten and collect them at the end of the day, meeting the staff at two critical points in the day's schedule. These two points of time are accompanied by stress on both sides. In the morning, the parents are in a hurry to get to work and the staffs are anxious to receive all the children and their parents in an appropriate manner. This helps the children and parents to 
experience a positive separation. At the end of the day, both the parents and the kindergarten staffs are in a hurry to get home after their working day and are not emotionally available to undertake any meaningful encounters concerning the child's progress or development. It is therefore essential to find a time when both parties are focused and available to engage in meaningful communication.

\section{Kindergarten Teacher-Parent Communication in the Digital Era}

In today's digital era, a great deal of interpersonal communication occurs through social networks such as SMS (Short Message Service), Email, Twitter, and more recently WhatsApp (Calvo, Iglesias, 2014). The use of social networks and other digital means of communication allow parents to become more involved in the kindergarten and its activities, and to communicate through different channels. Research has shown that the use of digital communication has enabled an increase in communication between parents and educational staff (Thompson, 2008). However, using technology in communications between parents and kindergarten teachers also has disadvantages. This is because the boundaries between the home and professional life and social life can become blurred (Agger, 2011). Research conducted by Palts and Kalmus (2015) indicated that it is essential to use a variety of channels for communication between educational staff and parents such as face-to-face meetings, electronic mail, and social networks. Each family should be able to choose what is the best channel for them.

\section{Communication using WhatsApp}

Maternal employment rates in OECD countries average 60\% (OECD Family database 2020). The need to be employed or the desire to work for self-fulfillment can cause parents feelings of guilt or pressure that they are not sufficiently involved in their child's life in the kindergarten. The use of social media such as WhatsApp can provide a sense of greater involvement. WhatsApp is an application that allows immediate communication through a number of platforms, messages, films, and photos. Thus, it has become highly popular in almost every walk of modern life. The use of WhatsApp for teacher-pupil communication has received significant research attention but not for communication between parents and kindergarten teachers.

This research will investigate how kindergarten teachers in Israel use the social media "WhatsApp" in their communication with parents.

Consequently, this research aimed to investigate the following questions: 
- How often do kindergarten teachers communicate with parents using the WhatsApp application?

- For what purpose do the kindergarten teachers use this application in their communication with parents?

- What are the kindergarten teachers' attitudes towards the use of the WhatsApp application in their communication with parents?

- Do more experienced kindergarten teachers reach out to parents using the WhatsApp application more frequently than less experienced kindergarten teachers?

\section{Method}

The research employed a quantitative research approach, using a questionnaire specially designed for this research. The questionnaire was distributed online as a Google.docs document to 161 kindergarten teachers in the North of Israel. The questionnaire consisted of questions that related to the kindergarten teachers' background and items that addressed the kindergarten teachers' use of the "Whatsapp" application in their communications with the parents of the children in their kindergarten. The questionnaire was checked for reliability through peer appraisal by five members of the academic staff of the authors' college, who are considered experts in early childhood studies.

\section{Participants}

Participants in this study were 161 kindergarten teachers. Most of them were working in the secular sector $(87.0 \%)$ and others in the religious (7.6\%) or private $(3.1 \%)$ sectors. As shown in Table 1 , about $40 \%$ of the teachers were in their forties, another quarter in their thirties, and another quarter in their fifties. Approximately $60 \%$ had a B.A. degree, and most of the others had an M.A. degree. Over a half of the teachers have been kindergarten teachers for over ten years, $23 \%$ have been kindergarten teachers for up to five years, and $20 \%$ for between six to ten years. Over a half of the kindergartens had 31-35 children, and about another third had 2130 children. All the teachers were women. 
Table 1. Background characteristics of the kindergarten teachers $(N=161)$

\begin{tabular}{|l|l|l|l|}
\hline \multirow{4}{*}{ Age } & Range & $N$ & $\%$ \\
\hline \multirow{5}{*}{ Education level } & $20-30$ & 14 & 8.7 \\
\cline { 2 - 4 } & $31-40$ & 40 & 24.8 \\
\cline { 2 - 4 } & $41-50$ & 64 & 39.8 \\
\cline { 2 - 4 } & $51-60$ & 41 & 25.5 \\
\cline { 2 - 4 } & $61-65$ & 2 & 1.2 \\
\hline Seniority, years of experience & B.A. & 96 & 59.6 \\
\cline { 2 - 4 } & M.A. & 64 & 39.8 \\
\cline { 2 - 4 } & Ph.D. & 1 & 0.6 \\
\hline Number of children in the kindergarten & $1-5$ years & 32 & 23.4 \\
\cline { 2 - 4 } & $6-10$ years & 28 & 20.4 \\
\cline { 2 - 4 } & $10-20$ years & 77 & 56.2 \\
\cline { 2 - 4 } & $10-15$ & 13 & 8.1 \\
\hline & $16-20$ & 10 & 6.2 \\
\cline { 2 - 4 } & $21-30$ & 54 & 33.5 \\
\cline { 2 - 4 } & $31-35$ & 84 & 52.2 \\
\hline
\end{tabular}

\section{Research Instruments}

\section{Communication with Parents}

A 13-item questionnaire was composed to assess the frequency of the kindergarten teachers' communication with the parents regarding various issues. Items included consideration of the following issues: updating parents about general and private events in and outside the kindergarten, answering parents' questions, sending photos of daily activities, and sending messages from the council or municipality. Items were rated on a four-point scale from 'seldom' (1) to 'daily' (4).

A principal component factor analysis with varimax rotation was performed for the different items. One major factor emerged, explaining $34.5 \%$ of the variance, and including 8 of the 13 items (62\%). Other factors included two items each, which loaded positively on the main factor as well (even though these were low loadings). Thus, a total score was composed of the mean for the different items representing the frequency of the kindergarten teachers' communication with the parents. The items were found to have a good internal consistency: $\alpha=.81$.

\section{Teachers' Attitudes toward the Use of WhatsApp and its Features}

The teachers' attitudes were measured according to their responses to several closed and open questions: 
1. The extent to which the kindergarten teacher considers herself open to change (yes/no/partly)

2. Would rather not use WhatsApp (agrees/disagrees/unsure)

3. Main goals for the use of WhatsApp ... (open question)

4. The use of WhatsApp may assist with... (open question)

5. Has defined the limits of WhatsApp use for the parents (yes/no)

6. Parents have a WhatsApp group that excludes the teacher (yes/no/doesn't know)

7. Sends activities for the parents to do with their children at home (yes/no)

\section{Demographic and Background Data}

There are collected data regarding the kindergarten teachers, which include type of kindergarten, age and years of experience, level of education, and the number of children in their kindergarten.

\section{Results}

Table 2 presents the findings concerning the kindergarten teachers' attitudes toward the use of WhatsApp and its features. Most teachers of about $90 \%$ considered they are open to change. Similarly, most $(62.5 \%)$ supported the use of WhatsApp, yet to a lesser extent and about a quarter were unsure if they supported or opposed its use.

Regarding the main goals of WhatsApp use, most teachers $(85 \%)$ noted that they use it to transfer information to the parents: messages about upcoming activities or events, important updates, and general information. In addition, teachers use WhatsApp to share the daily kindergarten experiences with the parents: sharing everyday contents and experiences with the parents, or sharing photos with the parents. A few teachers use it to share specific information about a child with his or her parents: personal messages, transferring information about the condition of a child, or sharing a photo of a child's activities that may encourage parent-child conversation.

The teachers were also asked about the advantages of the use of WhatsApp. Many commented that it is quick and readily available: "I can reach everyone very quickly", "send messages at the last minute", "receive a quick answer", and "available and accessible". Other teachers noted that it is an organized and effective form of communication: "effective communication - I know who read the message", "an effective way to communicate with all parents at once", "correspondence is documented", "convenient and direct communication", "continuous communication on a daily basis", "not all parents read emails or like to talk on the phone", and "[it] expedites procedures and saves paper". In addition, teachers noted that it allows them to share their daily contents and experiences with the 
children's parents: "sharing photos", or "increasing parents' involvement in the learning processes". Also, it assists in transferring information to the parents: "updates", "reminders", and "information".

Most teachers (81\%) have defined the limits of WhatsApp use to the parents, and most (79\%) reported knowing that the parents have a WhatsApp group that excludes them (the teacher). About two thirds of the teachers (68\%) send activities for the parents to do with the children at home.

Table 2. Teachers' attitudes toward the use of WhatsApp and its features $(N$ $=161)$

\begin{tabular}{|c|c|c|c|}
\hline Question & Response & $N$ & $\%$ \\
\hline \multirow[t]{3}{*}{ Open to change } & Yes & 142 & 89.9 \\
\hline & Partly & 11 & 7.0 \\
\hline & No & 5 & 3.2 \\
\hline \multirow[t]{3}{*}{ Would rather not use WhatsApp } & Disagrees & 100 & 62.5 \\
\hline & Unsure & 41 & 25.6 \\
\hline & Agrees & 19 & 11.9 \\
\hline \multirow[t]{3}{*}{ Main goals for the use of WhatsApp } & General information & 137 & 85.1 \\
\hline & Sharing & 71 & 44.1 \\
\hline & Information about a child & 6 & 3.7 \\
\hline \multirow[t]{4}{*}{$\begin{array}{l}\text { The use of WhatsApp may assist } \\
\text { with... }\end{array}$} & $\begin{array}{l}\text { Accessible, } \\
\text { communication }\end{array}$ & 69 & 42.9 \\
\hline & $\begin{array}{l}\text { Organized, effective } \\
\text { communication }\end{array}$ & 43 & 26.7 \\
\hline & Sharing & 57 & 35.4 \\
\hline & General information & 40 & 24.8 \\
\hline \multirow{2}{*}{$\begin{array}{l}\text { Has defined the limits of WhatsApp } \\
\text { use for the parents }\end{array}$} & Yes & 131 & 81.4 \\
\hline & No & 30 & 18.6 \\
\hline \multirow{3}{*}{$\begin{array}{l}\text { Parents have a WhatsApp group that } \\
\text { excludes the teacher }\end{array}$} & Yes & 126 & 78.7 \\
\hline & No & 20 & 12.5 \\
\hline & Doesn't know & 14 & 8.8 \\
\hline \multirow{2}{*}{$\begin{array}{l}\text { Sends activities for the parents to do } \\
\text { with their children at home }\end{array}$} & Yes & 110 & 68.3 \\
\hline & No & 51 & 31.7 \\
\hline
\end{tabular}

NOTE: Teachers were allowed to select several options in response to the open questions, and thus percentages exceed $100 \%$.

However, the teachers noted the frequency with which they used various ways of communication with the parents. The average score was $2.93(S D=0.49)$, ranging from 1 (seldom) to 4 (daily). This means that, on 
an average, communication with the children's parents was once a week. In Table 3, the distribution of the various types of communication is presented in descending order. Most common communications centered on answering the parents' general and individual questions, and it occurred daily for about $90 \%$ of the teachers. Next is sending messages to individual parents, or group messages. Thus, about $40 \%$ of the cases occurred once a week, and another $40 \%$ of the cases occurred daily. Updating the parents about activities and events in the kindergarten, and sending photos, usually occurred once a week $(50 \%$ to $60 \%)$. The frequency of using a "launch group" or sending information about activities outside the kindergarten varies and occurs on average between several times a month and once a week. Finally, the frequency of transferring information from the council or municipality about private events, or sending negative messages, varies as well with an average that is low.

Table 3. Extent of communication with the parents $(N=161)$

\begin{tabular}{|l|l|l|l|l|}
\hline & $\begin{array}{l}\text { Seldom } \\
\boldsymbol{N}(\%)\end{array}$ & $\begin{array}{l}\text { Several times } \\
\text { a month } \\
\boldsymbol{N}(\%)\end{array}$ & $\begin{array}{l}\text { Once a } \\
\text { week } \\
\boldsymbol{N}(\%)\end{array}$ & $\begin{array}{l}\text { Daily } \\
\boldsymbol{N}(\%)\end{array}$ \\
\hline $\begin{array}{l}\text { Answers to parents' general } \\
\text { questions to individual }\end{array}$ & $2(1.2)$ & $2(1.2)$ & $14(8.7)$ & $\begin{array}{l}143 \\
(88.8)\end{array}$ \\
\hline $\begin{array}{l}\text { Answers to } \\
\text { parents' questions }\end{array}$ & $3(1.9)$ & $3(1.9)$ & $11(6.8)$ & $\begin{array}{l}144 \\
(89.4)\end{array}$ \\
\hline Messages to the parents & -- & $9(5.6)$ & $\begin{array}{l}79 \\
(49.1)\end{array}$ & $\begin{array}{l}73 \\
(45.3)\end{array}$ \\
\hline Positive feedback & $11(6.8)$ & $21(13.0)$ & $\begin{array}{l}61 \\
(37.9)\end{array}$ & $\begin{array}{l}68 \\
(42.2)\end{array}$ \\
\hline Sending a group message & $16(9.9)$ & $16(9.9)$ & $\begin{array}{l}72 \\
(44.7)\end{array}$ & $\begin{array}{l}57 \\
(35.4)\end{array}$ \\
\hline $\begin{array}{l}\text { Update about activities in } \\
\text { the kindergarten }\end{array}$ & -- & $28(17.4)$ & $\begin{array}{l}96 \\
(59.6)\end{array}$ & $\begin{array}{l}37 \\
(23.0)\end{array}$ \\
\hline $\begin{array}{l}\text { Update about events in the } \\
\text { kindergarten }\end{array}$ & $4(2.5)$ & $34(21.1)$ & $\begin{array}{l}89 \\
(55.3)\end{array}$ & $\begin{array}{l}34 \\
(21.1)\end{array}$ \\
\hline Sharing photos of activities & $11(6.8)$ & $33(20.5)$ & $\begin{array}{l}82 \\
(50.9)\end{array}$ & $\begin{array}{l}35 \\
(21.7)\end{array}$ \\
\hline Using a launch group* & $\begin{array}{l}42 \\
(26.1)\end{array}$ & $18(11.2)$ & $\begin{array}{l}57 \\
(35.4)\end{array}$ & $\begin{array}{l}44 \\
(27.3)\end{array}$ \\
\hline $\begin{array}{l}\text { Information about activities } \\
\text { outside the kindergarten }\end{array}$ & $\begin{array}{l}24 \\
(14.9)\end{array}$ & $48(29.8)$ & $\begin{array}{l}68 \\
(42.2)\end{array}$ & $\begin{array}{l}21 \\
(13.0)\end{array}$ \\
\hline $\begin{array}{l}\text { Information from } \\
\text { council/ municipality }\end{array}$ & $\begin{array}{l}47 \\
(29.2)\end{array}$ & $37(23.0)$ & $\begin{array}{l}47 \\
(29.2)\end{array}$ & $\begin{array}{l}30 \\
(18.6)\end{array}$ \\
\hline
\end{tabular}




\begin{tabular}{|l|l|l|l|l|}
\hline $\begin{array}{l}\text { Information about private } \\
\text { events }^{+}\end{array}$ & $\begin{array}{l}61 \\
(37.9)\end{array}$ & $27(16.8)$ & $\begin{array}{l}49 \\
(30.4)\end{array}$ & $\begin{array}{l}24 \\
(14.9)\end{array}$ \\
\hline Negative feedback & $\begin{array}{l}76 \\
(47.2)\end{array}$ & $23(14.3)$ & $\begin{array}{l}35 \\
(21.7)\end{array}$ & $\begin{array}{l}27 \\
(16.8)\end{array}$ \\
\hline
\end{tabular}

*A launch group is a WhatsApp group in which only the group manager can issue messages to the members, but the members cannot react or send messages.

${ }^{+}$Private events take place outside the kindergarten, sometimes in the child's house or other venue.

Subsequently, several correlations were found between the study variables. First, seniority correlated positively with the frequency of communication with the parents $\left(r_{s}=.18, p=.039\right)$. Thus, teachers who had more years of experience in the job were more likely to communicate with parents more frequently.

Second, teachers who have defined the limits of WhatsApp use for the parents were more likely to communicate with the parents more frequently than teachers who have not defined the limits of WhatsApp use for the parents $(M=2.97, S D=0.48$ vs. $M=2.74 S D=0.49, t(159)=2.29, p$ $=.024)$.

Third, teachers who send activities for the parents to do with their children at home were more likely to communicate with the parents more frequently than teachers who do not send activities to do at home $(M=3.05$, $S D=0.43$ vs. $M=2.65 S D=0.49, t(159)=5.29, p<.001)$. These teachers were using WhatsApp more frequently for all other purposes as well, such as answering questions, sending messages, updating about events and activities, and sending photos $(p=.047$ to $p<.001)$.

\section{Discussion}

This paper aims to investigate the use of WhatsApp as a channel of communication between kindergarten teachers and the kindergarten children's parents. The research questions were as follows:

1. What are the kindergartens' teachers' attitudes to the use of the WhatsApp application in their communication with parents?

2. How often do kindergarten teachers communicate with parents using the WhatsApp application?

3. For what purposes do the kindergarten teachers use this application?

4. Do more experienced kindergarten teachers reach out to parents using the WhatsApp application, more frequently, than less experienced kindergarten teachers? 
In answering the first research question, the results indicated that a large percentage of the kindergarten teachers $(89.9 \%)$ use the application to communicate with parents, but within that large percentage there is a group of $25.6 \%$ that are unsure about the use of the application and another $11.9 \%$ that would prefer not to use the application. The literature indicates that there is ambivalence concerning the use of social networks for communication between educators and parents, stemming from the fear of blurred boundaries between professional and private life (Agger, 2011). This is also apparent in the results of the present study, which indicate that not all $(18.6 \%)$ the kindergarten teachers managed to define the limits for the use of the application. In addition, this ambivalence may be due to the fact that $78.8 \%$ of the teachers know that there is a separate group for parents, excluding the kindergarten teacher, while another $8.8 \%$ of the teachers do not know if such an independent group exists. The existence of such an independent group could cause stress and disagreement between the kindergarten teacher and parents, while the teacher remains unaware of the nature of the conversations that are being held by the parents in a group from which they are excluded.

In answering the second research question, it can be seen that $90 \%$ percent of the teachers reported that they conducted communication on a daily basis with the parents and this included messages that contained answers to parents' questions, either individually or as a group, and updates about activities in the kindergarten, including photographs. Less frequently, they sent messages from the local council and messages with a negative content. The use of the application for less personal messages is conducive for efficient interpersonal communication. Written messages are less easy to interpret than face-to-face interpersonal communication. Thus, it is impossible to see the non-verbal clues that play a major role in passing on messages in an efficient manner and help the recipient to interpret the message as intended.

In answering the third research question, the results show that the WhatsApp application is used by $85.0 \%$ of the teachers, who see the advantages of the use of the application in being able to transfer messages to a large group immediately and receive immediate replies. It is thought to be a quick and efficient means of communication with the parents, allowing the parents to become more involved, as expressed in previous literature in this field (Thompson, 2008).

In answering the fourth research question, it can be seen that the results of the present study show that the kindergarten teachers who were more experienced communicated more frequently with the parents, as did kindergarten teachers who defined the limits of the use of Whatsapp and 
kindergarten teachers who sent activities to do at home. These behaviors indicate that kindergarten teachers with experience and professional selfconfidence feel more at ease to reach out to parents. These kindergarten teachers were also using the WhatsApp application more frequently for other purposes, such as answering questions, sending messages, updating the parents concerning events and activities, and sending photos. This is contrary to what was found in extant literature (Gur \& Zalmson-Levi, 2005; Epstein \& Sheldon, 2002). The kindergarten teachers in the present study reported that they reached out to the parents to get their involvement and cooperation.

\section{Conclusion}

In conclusion, the kindergarten teachers reported that they are open to change and willing to adopt new technologies that can help them in their work. However, it appears that the main adoption and use of the WhatsApp tool is for the transmission of information or kindergarten experiences to the parents. Using this application empowers the communication between the teacher and the parents and constitutes a substitute for daily conversation that is usually performed at the end of the kindergarten day and very briefly. It is important to note and organize the issue of transfer of personal information or pictures on social media given the limitations of privacy on these networks. The kindergarten teachers felt that the WhatsApp application was especially advantageous because of its easy accessibility and speed of communication, and testify to more sharing and involvement of the parents in the life of their children in the kindergarten for so many hours each day. Despite all the advantages, several questions arise concerning mutual availability for the information that is transmitted, the type of information (pictures, experiences, information, assignments, etc.), and the extent of need for the use of this tool in the present era. During the last year, the Early Childhood Sector has been faced with tremendous challenges due to the worldwide pandemic following the COVID-19 virus. This has made it essential for kindergarten teachers to be able to communicate despite the various challenges. Now is also an opportunity to support new forms of integrated services that management responses show to be worthwhile (Mitchell et al., 2020). Here, the use of WhatsApp could certainly be beneficial as a form of online communication between parents and kindergarten teachers. 


\section{References}

Agger, B. (2011). iTime: Labor and life in a smartphone era. Time \& Society, 20(1), 119-136.

Baker, T. L., Kelly, G., Skiba, R. J., \& Wise, J. (2016). Identifying barriers: creating solutions to improve family engagement. School Community Journal, 26(2), 161, 163-184.

Bronfenbrenner, U. (1979). The ecology of human development, Harvard university press.

Calvo, R., Arbiol, A., \& Iglesias, A. (2014). Are all chats suitable for learning purposes? A study of the required characteristics. Procedia Computer Science, 27, 251-260.

Christenson, S. L. (2004). The Family-School Partnership: An Opportunity to Promote the Learning Competence of All Students. School Psychology Review, 33 (1), 83-104.

Epstein, J. (2001). School, family, and community partnerships. Boulder: Westview Press

Gur, H., \& Zalmanson-Levi, G. (2005). Parents and schools relationship: A criticism point of view. Education and Its Surroundings, 27, 131-142.

Kuusimäki, A. M., Uusitalo-Malmivaara, L., \& Tirri, K. (2019). Parents' and teachers' views.

Israel Ministry of Education (2003). Participation of parents in kindergartens: Analysis of questionnaires surveying expectations and needs. Jerusalem: Ministry of Education, Culture and Sport, Publications Department.

Mitchell, L., Meagher-Lundberg, P., \& Wells, C. (2020). Impact of Covid-19 on the early childhood education sector in Aotearoa New Zealand.

New, R. S., Mallory, B. L., \& Mantovani, S. (2000). Cultural images of children, parents and professionals: Italian interpretations of homeschool relationships. Early Education and Development, 11(5), 597616.

OECD Family database (2020). LMF1.2. Maternal employment rates Retrieved from http://www.oecd.org/els/family/LMF1_2_Maternal_Employment.pdf )

Palts, K. \& Kalmus, V. (2015). Digital channels in teacher-parent communication: The case of Estonia.Education and Development using Information and Communication Technology, 11, 3, 65-81.

Sword, A.D.E. (2014). Social media. Accountancy Ireland, 46(4).

Tal, K. \& Bar, T. (2010). Family-system relations. Education in early childhood from a historical viewpoint, background material for 
innovative work. $\quad$ Retrieved from:

http://education.academy.ac.i1/SystemFiles/23081.pdf

Thompson, B. (2008) Applying Social Information Processing Theory to

Parent Teacher Relationships Western Kentucky University, Bowling Green, KY. 